\title{
The Case of Rheumatoid Arthritis With Vasculitis
}

\author{
Sevcan UĞUR ${ }^{1}\left(\mathbb{D}\right.$, Cahit $\mathrm{KAÇAR}^{2}\left(\mathbb{D}\right.$, Ersel TURAN ${ }^{3}$ (D) \\ ${ }^{1}$ Department of Rheumatology, Ballkesir Atatürk City Hospital, Ballkesir, Turkey \\ ${ }^{2}$ Department of Rheumatology, Akdeniz University Faculty of Medicine, Antalya, Turkey \\ ${ }^{3}$ Department of Physical Medicine and Rehabilation, Akdeniz University Faculty of Medicine, Antalya, Turkey
}

Rheumatoid vasculitis (RV), characterized with necrotizing or leukocytoclastic vasculitis, is an unusual complication of long-standing rheumatoid arthritis (RA). RV is a serious extra-articular manifestation of RA that must be promptly recognized and treated. ${ }^{1}$ The aim of this report is to present the development of $\mathrm{RV}$ in a patient with long-standing and seropositive disease.

A 62-year-old female patient suffering from RA was admitted to the hospital with sudden onset of black-colored wounds. The lesions appeared as redness 10 days prior and became necrotic within three days. She had coronary bypass operation. There were three tender joints without swelling on musculoskeletal examination. The necrotic lesions were extending from the apex of fingers to metatarsus of the right foot and the big toe of left foot including both cruris (Figure 1). Hemoglobin was $10.6 \mathrm{gr} / \mathrm{dL}$, white blood cell was $12.6 \times 10^{3} / \mathrm{L}$, C-reactive protein was $20.6 \mathrm{mg} / \mathrm{L}$, erythrocyte sedimentation rate was $105 \mathrm{~mm} /$ hour, rheumatoid factor (RF) was $1230 \mathrm{IU}$, and complement and procalcitonin levels were normal. Punch biopsy was performed from left cruris and was consistent with vasculitis. She was diagnosed as RV. Intravenous methylprednisolone of $1 \mathrm{gr} /$ day was started. $\mathrm{T}$ wave negativity was detected on electrocardiography on the third day of intravenous methylprednisolone infusion. Ultrasensitive troponin level was high. The patient was diagnosed with myocardial infarction. Treatment was continued with oral prednisolone of $40 \mathrm{mg} /$ day and subcutaneous methotrexate of $15 \mathrm{mg} /$ week. At the follow-up appointment, she complained of coughing, fever and respiratory problems. A type virus (H1N1) was detected. A cytotoxic drug such as cyclophosphamide was not started due to A type virus (H1N1) infection. There were focal edematous signal changes and contrast enhancement in all metatarsal bones,

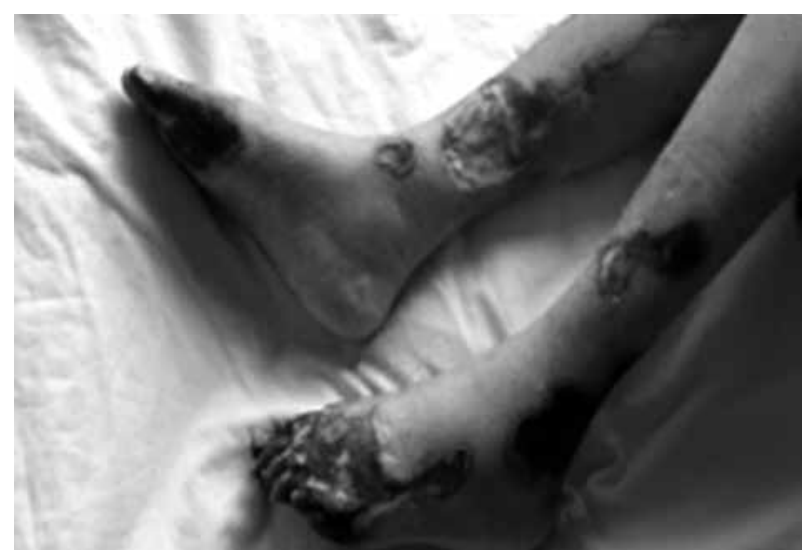

Figure 1. The necrotic skin lesions.

Received: February 18, 2018 Accepted: March 05, 2018 Published online: March 21, 2018

Correspondence: Sevcan Uğur, MD. Balıkesir Atatürk Şehir Hastanesi, Romatoloji Bölümü, 10100 Balıkesir, Turkey. Tel: +90 505 - 2642589 e-mail: dr_sevcanugur@hotmail.com 
calcaneus, talus, tibia, and cuboid bone on the left foot in magnetic resonance imaging. There were no improvement in wounds despite treatment with steroid and methotrexate. The patient was consultated with cardiovascular surgery department and they decided to amputate her foot.

Rheumatoid vasculitis is associated with long-term seropositive disease and is seen over 60 years of age. The risk is greater for men. ${ }^{2}$ Smoking, peripheral vascular disease, cerebrovascular disease, severe RA are among the well-known risk factors. ${ }^{3} \mathrm{RV}$ is associated with significant morbidity and mortality, it can affect both small and medium-sized vessels. ${ }^{1}$ The most common findings are cutaneous and neurological involvement. Small-vessel vasculitis involves skin and causes nail fold infarct, digital gangrene, and leg ulcers. ${ }^{4}$ Sensorial and/or motor neuropathy may be seen. Severe cardiac involvement such as myocardial infarction may be present. Rheumatoid synovitis may not be active when systemic vasculitis is present. $^{5}$ Majority of the patients have high titres of RF and anti-citrullinated peptide antibodies. ${ }^{4}$ High dose prednisone can be used. Cyclophosphamide treatment may be beneficial. Tumor necrosis factor inhibitors can be used with possibility of causing vasculitis. ${ }^{5}$ Our patient had a severe clinical picture. Because she had a heart attack during glucocorticoid treatment, amputation was needed. Although incidence of $\mathrm{RV}$ progressively declines with improvement in diagnosis and treatment of RA, prognosis still remains poor because of the lack of well-established treatment.

\section{Declaration of conflicting interests}

The authors declared no conflicts of interest with respect to the authorship and/or publication of this article.

\section{Funding}

The authors received no financial support for the research and/or authorship of this article.

\section{REFERENCES}

1. Kishore S, Maher L, Majithia V. Rheumatoid Vasculitis: A Diminishing Yet Devastating Menace. Curr Rheumatol Rep 2017;19:39.

2. Watts RA, Scott DG. Vasculitis and inflammatory arthritis. Best Pract Res Clin Rheumatol 2016;30:916-931.

3. Makol A, Crowson CS, Wetter DA, Sokumbi O, Matteson EL, Warrington KJ. Vasculitis associated with rheumatoid arthritis: a case-control study. Rheumatology (Oxford) 2014;53:890-9.

4. Turesson C, Matteson EL. Extraarticular features of rheumatoid arthritis and systemic involvement. In: Hochberg M, Silman A, Smolen J, Weinblatt M, Weisman M. Rheumatology. 6th ed. Philadelphia: Mosby Ltd; 2015. p. 712-19.

5. Turesson C, Jacobsson LT. Epidemiology of extraarticular manifestations in rheumatoid arthritis. Scand J Rheumatol 2004;33:65-72. 